\title{
Malignant Melanoma of the Temporal Bone Initially Presenting with Dizziness
}

\author{
Seunghoon Lee, Minju Kim, Dong Chang Lee, and Beom Cho Jun \\ Department of Otolaryngology-Head and Neck Surgery, The Catholic University of Korea College of Medicine, Uijeongbu, Korea
}

\author{
현기증을 동반한 측두골 악성흑색종 \\ 이승훈 · 김민주 · 이동창 · 전범조 \\ 가톨릭대학교 의과대학 이비인후과학교실
}

\author{
Received September 18, 2014 \\ Revised December 5, 2014 \\ Accepted December 12, 2014 \\ Address for correspondence \\ Dong Chang Lee, MD \\ Department of Otolaryngology-Head \\ and Neck Surgery, \\ The Catholic University of Korea \\ College of Medicine, \\ 271 Cheonbo-ro, \\ Uijeongbu 480-717, Korea \\ Tel $+82-42-220-9266$ \\ Fax $+82-42-221-9580$ \\ E-mail gadori@catholic.ac.kr
}

\begin{abstract}
Malignant melanoma of the temporal bone is a very rare disease. We report here a case of malignant melanoma of the temporal bone initially presenting as dizziness. The patient was a 48-yearold man presenting with dizziness. Physical examination showed horizontal nystagmus toward the left on the left lateral gaze and an intact tympanic membrane. Caloric tests demonstrated right-sided unilateral weakness. Vestibular neuritis was suspected, and conservative treatment was thus carried out. On follow-up, other symptoms were noted and the tumor of the temporal bone was diagnosed by computed tomography and magnetic resonance imaging of the temporal bone. This case shows that if the dizziness symptom is not improved after conservative management in patients who present with vestibular neuritis, an imaging evaluation could be necessary, taking into consideration the possibility of a tumor in the temporal bone.
\end{abstract}

Korean J Otorhinolaryngol-Head Neck Surg 2015;58(6):429-32

Key Words Dizziness $\cdot$ Malignant melanoma $\cdot$ Temporal bone.

\section{Introduction}

Malignant melanoma primarily affects the skin, but rarely affects the mucosa. Mucosal melanomas of the head and neck account for more than $1 \%$ of all melanomas, and mainly occurs at the oropharynx and the sinonasal cavity ${ }^{1-3)}$ melanoma of the temporal bone is a very rare entity. We herein present a case of malignant melanoma of the temporal bone initially presenting as dizziness.

\section{Case}

A 48-year-old male presented to the otolaryngology outpatient clinic with a 3-month history of dizziness. Physical examination showed horizontal nystagmus toward the left on left lateral gaze and an intact tympanic membrane. No other neurological abnormalities were observed in the neu- rology department consultation. Thus, vestibular neuritis was suspected, and conservative treatment (dimenhydrinate, flunarizine, and ginkgo biloba leaf extract) was thus carried out.

On follow-up after 1months, the dizziness symptom was maintained. Caloric tests were underwent and demonstrated right-sided unilateral weakness of $70 \%$. On the ENT outpatient department after 2 months, the symptoms had relapsed and right pulsatile tinnitus and diplopia were noted. Puretone audiometry showed mild, mixed-type hearing loss in the right ear. Computed tomography (CT) of the temporal bone showed a soft tissue density from the right mastoid to the petrous apex with bony erosion. The lesion extended to the middle ear cavity at the cochlear promontory (Fig. 1). Magnetic resonance imaging (MRI) revealed an approximately $4.5 \mathrm{~cm}$, irregularly contoured mass centered at the right petrous apex. The mass showed iso-to-low signal intensity on T2-weighted images and heterogeneous high-signal 
intensity on gadolinium-enhanced T1-weighted images (Fig. 1).

A glomus tumor or malignant tumor was suspected, and the patient underwent tumor excision via a retrolabyrinthine approach and mastoidectomy with craniotomy conducted by the neurosurgery team. During the surgery, a fibrotic dark gray mass was found to involve the mastoid and middle ear, and it was adhered to the mastoid segment of the facial nerve. Frozen biopsy was performed. Frozen sections suggested malignant melanoma. Examination of hematoxylin- and eosin-stained sections showed that the tumor cells varied in shape and size (Fig. 2A). On immunohistochemical examination, the tumor cells were positive for S-100 protein and HMB-45 (Fig. 2B). The overall features were consistent with malignant melanoma.

To exclude metastatic melanoma, additional evaluation was carried out. On thorough examination, no pigmented lesions
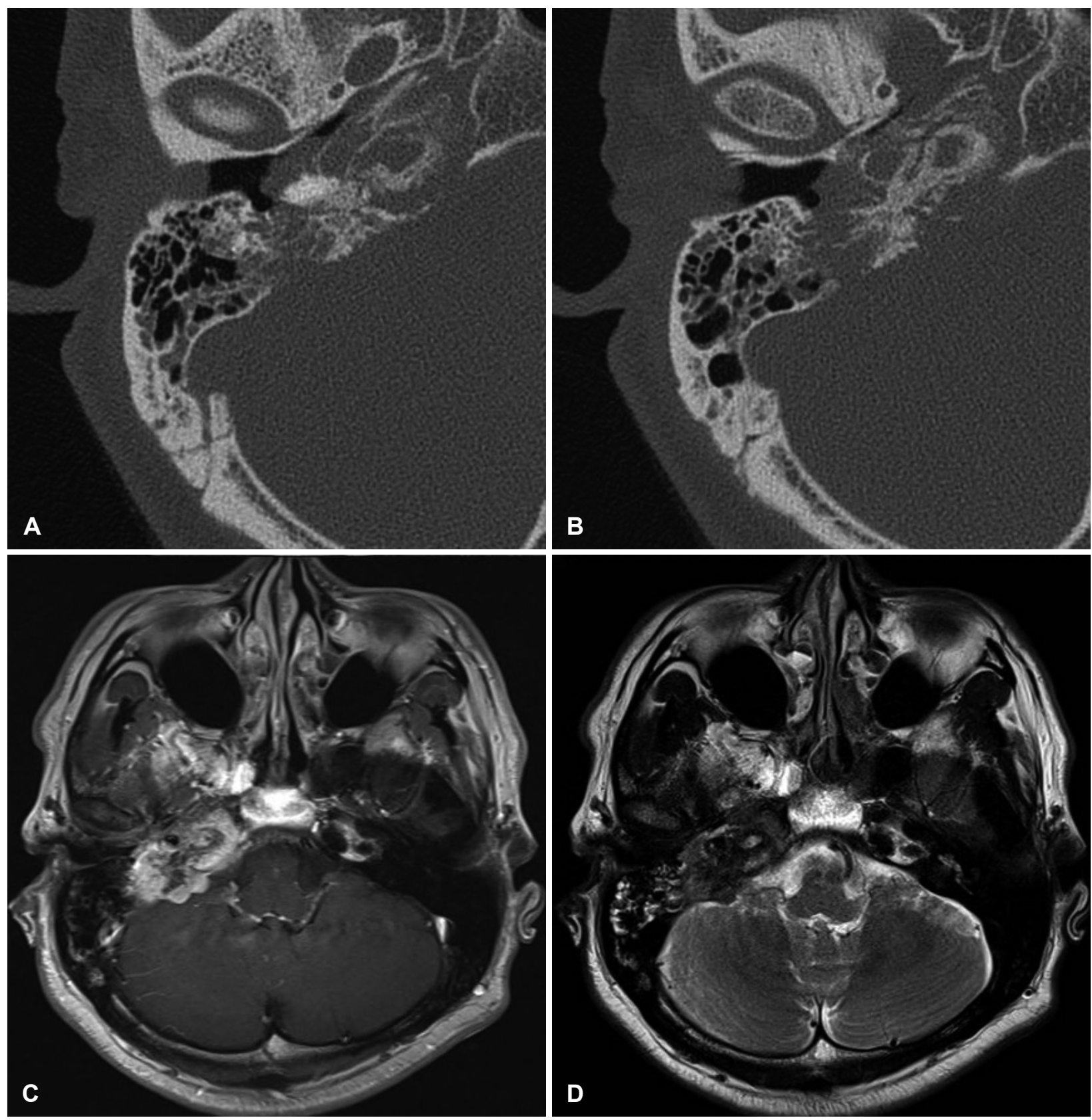

Fig. 1. Computed tomography (CT) of the temporal bone showed a soft tissue density from the right mastoid to the petrous apex with bony erosion. The lesion extended to the middle ear cavity at the cochlear promontory (A and B). Magnetic resonance imaging (MRI) revealed an approximately $4.5 \mathrm{~cm}$, irregularly contoured mass centered at the right petrous apex. The mass showed heterogeneous high-signal intensity on T1-weighted images (C) and iso-to-low signal intensity on T2-weighted images (D). 


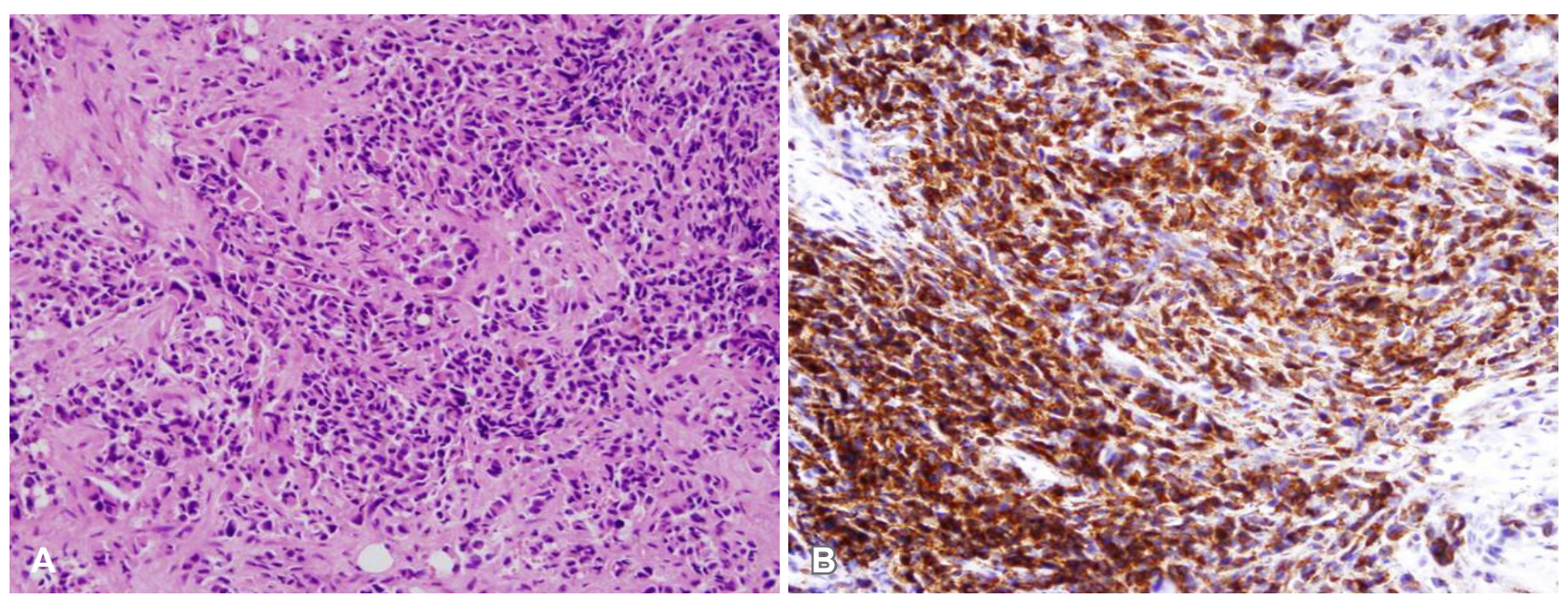

Fig. 2. The tumor comprised ovoid- to spindle-shaped cells showing prominent nucleoli and vesicular nuclei (A: hematoxylin and eosin, original magnification, $\times 200$ ). On immunohistochemical staining, the tumor cells were strongly positive for melanoma antibody HMB-45 (B: HMB-45 stain, original magnification, $\times 200$ ).

were found. We performed positron emission tomography$\mathrm{CT}$ and a bone scan to rule out metastatic disease. No other lesions were identified.

After surgery, right facial weakness (House-Brackmann grade III) was observed. The patient received intensity-modulated radiotherapy (6480 cGy) and chemotherapy with high dose interferon- $\alpha$. After radiotherapy, he complained of severe headache and showed decreased mentality. Six months after the operation, the patient died of disease progression, pneumonia, and sepsis.

\section{Discussion}

In this case, the origin of the melanoma was presumed to be the middle ear mucosa, based on CT and MRI findings. Acorrding to MRI study, the dizziness might be developed secondary to inflammatory change around tumor or direct invasion of the vestibular nerve in the internal auditory canal. We supposed that the diplopia was caused by cranial nerve VI (abducens nerve) palsy because the tumor had already expanded to the petrous apex where the abducens nerve pass.

Carcinomas in various sites throughout the body are known to metastasize to the temporal bone, most frequently from the breast, kidney, and lung. ${ }^{4}$ Likewise, malignant melanoma is known to metastasize to the temporal bone. Malignant melanoma accounts for $1 \%$ of all malignancies ${ }^{5)}$ and is characterized by the ability to diffusely metastasize. However, primary malignant melanoma of the middle ear mucosa is extremely rare; only six reports have been published. ${ }^{6-11)}$

Most studies have shown that radical resection of the pri- mary tumor with negative margins may provide the best therapeutic results for head and neck mucosal melanoma. However, negative margins can be very difficult to obtain due to microscopic spread that cannot be identified grossly. Postoperative radiotherapy improves locoregional control, but does not improve survival. Definitive radiotherapy with high linear energy achieves locoregional control rates comparable with those achieved surgically. Biochemotherapy with interferon- $\alpha$ or interleukin-2 improves survival in patients with mucosal melanoma of the head and neck. ${ }^{12)}$

In other cases, the presenting symptoms include hearing loss, otorrhea, aural fullness, otalgia, pulsatile tinnitus, and facial paralysis. ${ }^{6}$ However, in this case, the patient's chief complaint was dizziness without any other otologic symptoms. We treated the patient conservatively under the impression of vestibular neuritis. However, other symptoms developed later, suggesting the presence of a tumor. In this case, an initial imaging work-up and continuous follow-up of the subjective symptoms must have been carried out.

The temporal bone tumor may be overlooked because of the very low incidence. Therefore, if the dizziness symptom was not improved after the conservative treatment and the continuous assessment of the subjective symptoms in patients who presents with vestibular neuritis, an imaging evaluation can be needed, taking into consideration the possibility of a tumor in the temporal bone.

\section{REFERENCES}

1) Chang AE, Karnell LH, Menck HR. The National Cancer Data Base report on cutaneous and noncutaneous melanoma: a summary of 84 , 836 cases from the past decade. The American College of Surgeons 
Commission on Cancer and the American Cancer Society. Cancer 1998;83(8):1664-78.

2) Lee HS, Yi JS, Lee BJ. Mucosal melanoma of the sinonasal tract: retrospective analysis of 38 patients of a single institution. Korean J Otorhinolaryngol-Head Neck Surg 2014;57(6):384-9.

3) Hong SL, Kim SW, Won TB, Shim WS, Kim YM, Kim JW, et al. Clinical features and treatment outcomes of mucosal malignant melanomas of nasal cavity and paranasal sinuses. Korean J Otolaryngol-Head Neck Surg 2006;49(12):1176-80.

4) Hill BA, Kohut RI. Metastatic adenocarcinoma of the temporal bone. Arch Otolaryngol 1976;102(9):568-71.

5) Kingdom TT, Lalwani AK, Pitts LH. Isolated metastatic melanoma of the cerebellopontine angle: case report. Neurosurgery 1993;33(1):142-4

6) Peters G, Arriaga MA, Nuss DW, Pou AM, DiLeo M, Scrantz K. Mucosal melanoma of the middle ear cavity and Eustachian tube: a case report, literature review, and focus on surgical technique. Otol Neurotol 2012;33(2):239-43.
7) Oztürk O, Bağlam T, Uneri C, Küllü S. Primary malignant melanoma of the middle ear mucosa: a case report. Kulak Burun Bogaz Ihtis Derg 2006;16(2):83-6.

8) Urpegui García A, Lahoz Zamarro T, Muniesa Soriano JA, Vallés Varela H, Martínez Subías J, Sancho Serrano E, et al. [Malignant melanoma of the middle ear, a rare site]. Acta Otorrinolaringol Esp 1999; 50(7):559-62.

9) Sherman IW, Swift AC, Haqqani MT. Primary mucosal malignant melanoma of the middle ear. J Laryngol Otol 1991;105(12):1061-4.

10) McKenna EL Jr, Holmes WF, Harwick R. Primary melanoma of the middle ear. Laryngoscope 1984;94(11 Pt 1):1459-60.

11) Uchida $M$, Matsunami $T$. Malignant amelanotic melanoma of the middle ear. Arch Otolaryngol Head Neck Surg 2001;127(9):1126-8.

12) Moreno MA, Hanna EY. Management of mucosal melanomas of the head and neck: did we make any progress? Curr Opin Otolaryngol Head Neck Surg 2010;18(2):101-6. 